by their hospital surroundings and by the process of depersonalisation into accepting any indignities without embarrassment. That may be so, but what of the outpatient who has just walked in off the street and is still bound by the taboos of the outside world? Although my own examination was one that did not require me to undress, I was disturbed to see other outpatients being obliged to strip off in cubicles situated in a waiting area occupied by patients (and accompanying relatives) of both sexes, on a public corridor. It must have felt like having to undress at a bus stop. Within earshot of all and sundry they were told by the nurse which garments they had to remove, and then had to emerge attired in skimpy hospital gowns (no dressing-gowns being provided), their own clothes bundled in their arms. I felt particularly humiliated on behalf of an elderly man who looked ludicrous in a little white nightie.

I am sure the medical and nursing care given to hospital patients is exemplary, but I am worried by what seems to be an indifference towards patients' susceptibilities. One reason why its "regulars" so cherish the Elizabeth Garret Anderson Hospital is because it goes to great pains to avoid embarrassing patients. Surely it must be possible, without any trouble or financial outlay, to put undressing cubicles in places more secluded than a public highway. Most outpatients are already nervous about their condition and intimidated by hospital surroundings; they should not be subjected to unnecessary embarrassments and indignities.

Romford, Essex

Pamela HarRis

Asthma and climatic conditions: experiences from Hong Kong

SIR,-There seems little doubt from the contributions to your journal (4 October, p 843; 8 November, p 1239) and other studies that asthmatic attacks are far from uniform in their frequency over the year.

In 1984 we investigated the pattern of admission of children with asthma to the wards of a busy general hospital in Kowloon, the Caritas Medical Centre, over the four years 1980-3. 'In 993 patients we found a clear bimodal distribution of admissions for asthma with an autumn wave peaking in November and a smaller spring wave reaching a peak in May (figure).

Pursuing possible explanations for these seasonal variations we analysed the admissions in relation to six climatic factors: temperature, air pressure, humidity, rainfall, sunshine, and windspeed ${ }^{2}$ (information obtained by courtesty of the Royal Observatory, Hong Kong). With a multiple stepwise regression analysis the best model containing two climatic variables was found: number of admissions $=51 \cdot 41-0 \cdot 26 \mathrm{D}_{\text {rain }}$ $+14.2 A D_{\text {temp }}\left(D_{\text {rain }}=\right.$ difference in monthly rainfall; $\mathrm{AD}_{\text {temp }}=$ absolute difference in monthly temperature); $F$ value 0.75 .

Thus about $75 \%$ of the variation in the number of admissions can be attributed to rainfall and temperature (figure). Any change in rainfall would affect asthmatic admissions in the opposite direction-that is, increased rainfall lessening the number of admissions, reduced rainfall increasing them. Any change in environmental temperature in either direction would increase admission rate.

The mechanism(s) whereby these climatic changes bring about asthmatic attacks is (are) unknown. They may simply exist concomitantly with, but not directly cause, asthmatic attacks. The smaller admission peak in late spring might be due to an increase in pollen, fungal spores, and other aeroallergens at a time when the temperature is changing from cool to warm and when rainfall is only moderate. In Hong Kong the summer months bring relatively little fluctuation in monthly temperature but a consistently steady amount of rainfall. Regular rainfall will wash airborne allergens from the air, thereby lessening chances of inhalation. Rainfall is also accompanied by temperature inversions which tend to force particles nearer to the ground. These factors might explain the trough of asthmatic admissions in July and August. (It is relevant here to recall Derrick's experience in Brisbane, in which he describes fewer attendances with asthma on wet days. ${ }^{3}$ ) With the coming of autumn in October and November the gradual influx of a cold dry air mass resulting in much less rainfall might be responsible for a big wave of admissions from a resultant increase in levels of fungal and pollen spores and even air pollutants, which gain less impeded entry into the lungs. The colder weather itself might also have an added effect in increasing bronchial lability either from direct action on the respiratory mucosa or indirectly by reactivating dormant viruses. The small peak in May, which appears to parallel the increase in rainfall at this time, might seem to contradict the rainfall hypothesis. However, a particular type of pollen (or other airborne allergen) might have its principal effect in the spring despite steadily increasing rainfall.

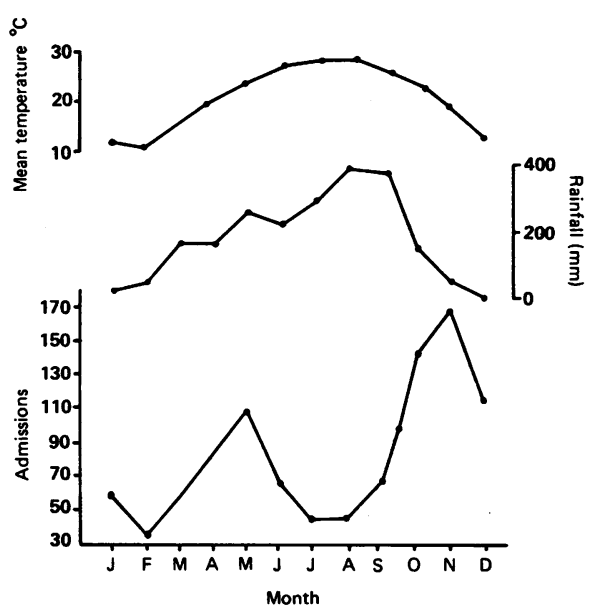

Monthly asthmatic admissions (1980-3) to paediatric wards of Caritas Medical Centre, Hong Kong, in relation to mean monthly rainfall and temperature. (Reproduced by courtesty of the editor, Hong Kong fournal of Paediatrics.)

These ideas are but an endeavour to account for the well defined seasonal variations in admissions to hospital for asthma. There are probably other interpretations. They do, however, conform in large part with other opinions to explain seasonal changes in asthma. ${ }^{4}$ Nevertheless the interesting theories put forward to explain the seasonal variations should not detract from their important clinical implications-namely, that children (and adults) who suffer from asthma must have special attention given to prophylaxis and early treatment of attacks during a season of particular vulnerability.

\section{Department of Paediatrics,}

K W WONG Caritas Medical Centre, Kowloon

Department of Paediatrics,

D P DAviES

Department of Community Medicine, Chinese University of Hong Kong, Shatin, NT, Hong Kong

1 Wong KW, Davies DP. Seasonal variations in childhood asthma Hong Kong foumal of Paediatrics 1985;2:19-23.

2 Wong KW, Davies DP, Lau EMC. Asthmatic admissions. Hon Kong Joumal of Paediatrics 1985;2:272-4.

3 Derrick EH. The short term variation of asthma in Brisbane: its relation to the weather and other factors. Int $\mathcal{J}$ Biometeor 1969;13:295-301.

4 Derrick EH. Asthma and the Brisbane climate. Aust NZ J Med 1972;3:235-46.
Why women are not receiving anti-Rh prophylaxis

SIR,-Dr Marcela Contreras and colleagues (22 November, p 1373) suggest that failure to give anti-Rh immunoglobulin after spontaneous abortion is common and that it accounts for many cases of $\mathrm{Rh}$ sensitisation. Tovey showed that $22 \%$ of new cases of sensitisations were due to failure of administration, and of these one half arose after spontaneous or therapeutic abortion. ' However, a recent audit conducted in the Mersey Region does not confirm these observations.

Medical records of new sensitisations arising in the Mersey region in 1983 and 1985 were examined. There were 81 cases and of these $36(44 \%)$ arose because of failure of protection-that is, the patients were given the standard postnatal or postabortion dose of anti-D immunoglobulin but nevertheless developed antibodies by or during the next pregnancy; 11 cases (14\%) arose in primigravidas during the pregnancy; and six (7\%) were in women whose last pregnancy was before the widespread use of anti-D immunoglobulin. However, only five cases (6\%) arose because of a failure to administer anti-D immunoglobulin-three were failures of administration after a full term pregnancy and the remaining two were after spontaneous and therapeutic abortions. The remaining 23 patients "booked" with antibodies but their history with regard to anti-D immunoglobulin was unknown. Some of these cases may have been due to failure to administer anti-D immunoglobulin when indicated.

Although failure to administer anti-D immunoglobulin still accounts for some new sensitisations, this does not seem to be due particularly to failure of administration after early spontaneous abortion. A substantial number of sensitisations arise from failure of protection, which may be the result of insufficient anti-D immunoglobulin having being given. As there is currently a shortage of anti-D immunoglobulin perhaps attention should be focused on the reasons for failure to administer after full term delivery and therapeutic abortion as well as on cases where insufficient anti-D immunoglobulin has been given.

RUTH M HUSSEY

Department of Community Health,

University of Liverpool,

Liverpool L69 3BX

1 Tovey LAD. Haemolytic disease of the newborn-the changing scene. Br J Obstet Gynaecol 1986;93:960-6.

\section{Hip fractures in healthy patients}

SIR,-Mr R Villar and colleagues put forward a case for treating subcapital femoral neck fractures as "middle of the night" emergencies ( 8 November, $p$ 1203).

Assessing the results of hip surgery must not be based entirely on social and rehabilitation grounds. There are other reasons for a protected environment that can confuse the hip result. The three recovery categories of Hall and Ainscow are disheartening if related purely to the fracture treatment. In many cases geriatric falls and fractures are the first outward manifestation of what should be an already lowered grading of this type-that is, the changes in the patient or her environment that require a drop in grading are often the precipitating factors of the fracture. Mr R Villar and colleagues suggest the patient's failure to give consent as one reason for delay in surgery, but this strongly suggests that preoperatively factors are already at work necessitating a lowering of independence grade. Delayed diagnosis was another reason given, but in many of these cases the 